\title{
Recent Progress in Modeling Solid Propellant Combustion
}

\author{
M. W. Beckstead ${ }^{1}$
}

UDC 536.46

Translated from Fizika Goreniya i Vzryva, Vol. 42, No. 6, pp. 4-24, November-December, 2006.

Original article submitted May 31, 2006.

Tremendous progress has been achieved in the last ten years with respect to modeling the combustion of solid propellants. The vastly increased performance of computing capabilities has allowed utilization of calculation approaches that were previously only conceptual. The paper will discuss three areas of emphasis: first, numerical modeling of premixed flames using detailed kinetic mechanisms; second, development of packing models to calculate a geometrical distribution of particles simulating a heterogeneous solid propellant; and finally, calculation of diffusion flame effects that are critical in the combustion of AP/hydrocarbon solid propellants.

The capability of modeling premixed combustion using detailed kinetic mechanisms has been evolving and successfully applied to solid propellant ingredients based on a one-dimensional approach. Much of the early work was performed at Novosibirsk. The approach allows calculating the burning rate as a function of pressure but also the temperature sensitivity and spatial distributions of temperature and species concentrations. Generalized mechanisms have been developed and applied to many ingredients such as HMX, GAP, RDX, NG, AP, etc. The gas-phase kinetic mechanisms seem to represent the chemistry of these monopropellants and pseudo-propellants consistently well. The burning rates of these monopropellants vary by almost an order of magnitude but are essentially independent of the flame temperature. Various model calculations agree reasonably well with available experimental data.

Recent work in the USA has been aimed at describing the geometrical packing of a solid propellant. These models represent significant progress toward such a description. Combining the packing model with a realistic flame model is still a significant challenge. Preliminary results are encouraging, but obviously further work is needed. Also, fundamental calculation of two-dimensional diffusion flames, incorporating realistic kinetics has progressed significantly. Recent results show encouraging promise toward simulating the minute detail involved in determining the burning rates of AP containing propellants.

Key words: modeling, combustion, solid propellant, chemical kinetics.

Abbreviations
\begin{tabular}{l|ll|l} 
ADN & ammonium dinitramide & HMX & cyclotetramethylene tetranitramine \\
AMMO & 3-azidomethyl-3-methyl oxetane & NG & nitrocellulose \\
AP & ammonium perchlorate & NMMO & 3-nitratomethyl-3-methyl oxetane \\
BAMO & $3,3^{\prime}$-bis(azidomethyl)oxetane & PETN & pentaerythritol tetranitrate \\
BTTN & $1,2,4$-butanetriol trinitrate & PGN & polyglycidyl nitrate \\
CTPB & carboxyl-terminated polybutadiene & PVN & polyvinyl nitrate \\
GAP & glycidyl azide polymer & RDX & cyclotrimethylene trinitramine \\
HTPB & hydroxyl-terminated polybutadiene & TEGDN & triethylene glycol dinitrate \\
& & TMETN & trimethylolethane trinitrate
\end{tabular}

\footnotetext{
${ }^{1}$ Brigham Young University, Provo, Utah, USA; mwb@caedm.byu.edu/
} 


\section{INTRODUCTION}

Combustion of solid propellants involves a combination of processes evolving from various ingredients that constitute the propellant. These ingredients decompose, evaporate and/or pyrolyze, giving off gases, which then react, resulting in energetic flames that drive the combustion process of the propellant. During the past two decades, tremendous progress has been made in developing reaction mechanisms, the methodology for developing the corresponding kinetic data, and the models to describe various aspects of propellant combustion. The greatest achievement has been made in the development of the overall process for describing the premixed flames associated with virtually all of the ingredients that constitute typical solid propellants. Most of the individual ingredients used in solid propellants burn as monopropellants [1]. This paper summarizes the recent research that has focused on developing kinetic models describing the combustion of many of these ingredients.

Combustion of a monopropellant can be divided into three regions (condensed region, liquid-gas twophase region, and gas region) $[2,3]$. Monopropellants can sublime and/or decompose while in their solid form, but the rates associated with these processes are usually small compared to the decomposition and evaporation rates after the propellant has melted. The two-phase (molten) region consists of liquid and gaseous species resulting from melting and/or decomposition of the solid phase. For example, both RDX and HMX form a visible, definitely liquid layer [4], and during combustion there are hardly any effective reactions contributing to the combustion process below the melt temperature. For AP it is less well defined. The melt layer is not directly observable, and the melt temperature has not been determined, other than by inferences.

The precise division between the two-phase and gas-phase regions (i.e., the "burning surface") is also not well defined due to chemical reactions, bubbles, and condensed material being convected away from the surface. In the gas-phase region of a monopropellant, the flame is essentially premixed. The species emanating from the surface react with each other and/or decompose to form other species. A wide variety of reactions involving many species occur in the gas flame [5] until thermodynamic equilibrium is reached in the final flame zone.

More complexity is introduced with heterogeneous propellants containing multiple ingredients. In some cases, a whole new set of reactions may occur. In other cases, the reactions are essentially the same as if the monopropellants were burning separately. Some ingre- dients, such as RDX, burn with a thick surface melt layer, while others, such as GAP, burn with little or no surface melt layer. Thus, the burning surface and the heat feedback from the flames to the surface can be significantly different from the monopropellant case. Therefore, it is important to understand the geometric distribution of various ingredients that make up a propellant and their effects on the combustion. Various numerical models have recently been developed in an attempt to predict these geometric effects of composite propellants (see the discussion in the next section). These models have progressed through various levels of complexity, from one-dimensional to multi-dimensional models and from global or semi-global gas-phase kinetics to detailed reaction mechanisms.

One of the desirable characteristics of AP composite propellants is the dependence of their burning rates on the size distribution of particles used. The Beckstead-Derr-Price (BDP) model [6] assumes a three-flame structure: the primary diffusion flame between the AP decomposition products and the binder decomposition products; the AP monopropellant flame; and the final diffusion flame between the AP monopropellant flame products and the binder products (mixed with the primary diffusion flame products). The primary diffusion flame is assumed to be a dominant driving force in AP composite propellant combustion.

In order to investigate in detail the interactions between self-deflagration and diffusion flames, a multidimensional model with detailed chemical kinetics has recently been developed. This two-dimensional model also provides a framework in which detailed kinetic mechanisms can be developed and applied to premixed and diffusion flames above an idealized burning propellant.

\section{PREVIOUS MODELING SUMMARY}

The evolution of steady-state propellant combustion modeling can be divided into three general categories: 1) models based on global kinetics; 2) semiglobal models based on some finite-rate kinetic mechanisms in either, or in both, gas and condensed phases; 3) multi-phase models with detailed kinetic mechanisms.

Naturally, some models can overlap categories. Global kinetics-type models typically only solve the energy equation using a flame sheet or flame standoff distance approach. Most of these modeling efforts date to the 1960s-1970s. Semi-global models using some kind of finite-rate kinetic mechanisms have usually (but not always) relaxed the flame sheet assumption, replacing it 
with a distributed energy release associated with solving both the energy and species equations. These were typical efforts of the 1970s-1980s. Virtually all of the models were able to match the experimental burning rate data with reasonable accuracy in spite of the diverse assumptions relative to the physical picture being modeled. As a result, most researchers then claimed that their physical model was "correct" based on the agreement. All of the models contain parameters, usually related to the kinetic expressions, that have not been quantified experimentally and, thus, must be estimated to ensure a reasonable fit of the data. This "fitting" process ensures reasonable agreement between modeling and experiments. These models have been reviewed and summarized in several papers $[1,7-9]$ noting that a reasonable fit of the experimental data does not justify a claim that the model is "correct." A wellgrounded model should allow one to examine the effect of various parameters other than just burning rate, such as temperature sensitivity, energy release distribution, pressure exponent, etc.

Buckmaster, Jackson and co-workers have developed a two- and three-dimensional methodology to describe the geometric effects within solid propellants [10-16]. The complex unsteady heat transfer and propellant-surface regression through oxidizer/binder sandwiches, and two-dimensional and three-dimensional random packs of propellant particles have also been modeled using 2- and 3-step global reaction mechanisms to describe the gas-phase heat release. The results of [10-16] will be discussed below.

In order to model AP-HTPB propellants, twodimensional models are required to describe the diffusion flame structure associated with AP [17-19]. Recent work has been done on modeling diffusion flames for propellants with complex particle packing [20]. The physical models of concern are sufficiently complex, which most often requires very simplified, semi-global kinetics.

\section{MONOPROPELLANT MODELS BASED ON DETAILED KINETICS}

The most recent models include detailed reaction mechanisms in the gas phase, coupled with a distinct description of the condensed phase. These types of models were first developed in the 1980s and were initially applied primarily to HMX and AP. A brief summary of those early models can be found in [1]. In 1995, Cor and Branch [21] also reviewed several of these models, with emphasis on those that were based primarily on the Miller-Bowman mechanism [22].
Fifteen to twenty years ago, the CHEMKIN/PREMIX software [23, 24] was developed, establishing a standard format that facilitates the solution of the gas-phase equations for multiple reactions. Combined with the fact that the computing capability has grown and continues to grow exponentially, further development of detailed kinetic models has accelerated. The improved computing capabilities have also fostered the capability for utilizing quantum and statistical mechanics methods to calculate the required chemical kinetics for the gas-phase reaction steps, which has furthered the development of this approach.

Various models found in the literature employing detailed kinetics include models for one- and twodimensional steady-state treatment and one- and twodimensional unsteady-state treatment. Most of the models are for a one-dimensional steady-state monopropellant, and this paper focuses on those modeling studies. Most models are aimed at calculating the burning rate and temperature and species profiles at varying pressures. One-dimensional transient models have also been developed to simulate processes such as oscillatory combustion [25, 26], ignition [27-30], and fast cook-off [31].

In the last section, models simulating pseudopropellants will be considered. A mixture of two or more ingredients is considered as a pseudo-propellant if it can be assumed that the mixture is homogeneous. This should be a reasonable assumption if there are no particles or if the particulate phase is of the order of ten microns or smaller. Satisfying these two assumptions should yield a mixture that can be considered homogeneous, allowing the premixed flame equations to be employed.

\section{Basic Approach}

The basic approach has been developed to model a three-phase system, which includes the solid phase, the condensed (liquid-gaseous) phase, and the gas phase. The gas-phase flame provides a heat source, which, along with the condensed-phase heat release, drives the combustion process.

Condensed Phase. Depending on the ingredient modeled, the solid phase is assumed to extend toward the surface until either melting or significant decomposition starts. Most of the models assume that no reactions occur in the solid phase. Therefore, only the energy equation needs to be solved for the solid phase $[2,3]$. $\mathrm{AP}$ is an exception: its decomposition is observed to occur in the solid phase, well below the melt condition. Thus, for AP, solid-phase decomposition must be considered. The liquid condensed phase containing bubbles 
is the least understood one of the three phases. Consequently, there has been significant variation in modeling the condensed phase. In particular, the gases formed within the condensed phase were assumed to be dissolved in the liquid, while Liau et al. [3] and Davidson et al. [2] modeled the gases within the condensed phase as bubbles and treated them using a void-fraction approach. The energy, species, and continuity equations are usually solved for the condensed phase [39].

Miller and Anderson have recently used a muchsimplified condensed-phase analysis [32], similar to what Korobeinichev and his associates have used (e.g., see $[33,34])$. The Russians [33, 34] have typically measured the surface temperature and the concentrations of the major species leaving the surface at some low pressure. They then use these experimentally determined values as the boundary condition fed into the gas-phase equations. Thus, their calculations only apply to the pressure where the measurements were made, or they must assume that the conditions do not change with pressure. In the Miller-Anderson approach [32], they assume that all condensed-phase reactions can be described by a boundary condition. Thus, they do not have to solve the conservation equations in the condensed phase. Based on observed experimental data and intuition, Miller and Anderson [32] assume a distribution of species leaving the surface, which will be representative of the reactions and evaporation that occur in the condensed phase. They also assume an Arrhenius pyrolysis relationship between the mass burning rate and the surface temperature. This second assumption is based on experimental observations that relate the burning rate to the surface temperature (e.g., universal pyrolysis law [35] for NG containing propellants). This is very similar to the assumption made in the majority of the global and semi-global models of the past [1].

Another recent approach in modeling the condensed phase includes a description of the surface tension of the bubbles in the liquid layer [36, 37]. Using that approach allowed the successful calculation of the difference in the temperature sensitivity of RDX and HMX at low pressures, which has been observed experimentally. Previous models had not been very successful in predicting that difference between RDX and HMX.

Gas Phase. The approach used by most researchers to model the gas phase has been very similar $[2,3,32$, $38,39]$. A slightly modified version of the PREMIX program [24] has usually been used, solving the energy, species, and continuity equations including a detailed reaction mechanism. Detailed kinetics (radical-chain reactions) and temperature-dependent thermophysical properties (for gas-phase equations) are obtained from independent sources.
In 1995, Yetter and co-workers [38] reviewed kinetic data for several flames and the pertinent reaction steps to describe those within the $\mathrm{C} / \mathrm{H} / \mathrm{O} / \mathrm{N}$ system that were anticipated to apply to solid ingredients. They developed a reaction mechanism for RDX that was based on 45 species and 232 reaction steps. This mechanism provided a basis for much of the work that has followed.

Some of the boundary conditions, especially between the condensed phase and gas phase are handled differently in different models. For most of the models, the burning rate is considered an eigenvalue, and convergence is achieved by matching the calculated heat fluxes between the gas and condensed phases. The complexity and size of the gas-phase chemical kinetic mechanisms has increased over the years, which has resulted in more detailed and accurate model calculations.

\section{Shortcomings}

The results from these models enhance the understanding of the combustion processes, and the potential of these models to evolve into a predictive tool appears promising. However, insufficient understanding of the condensed phase, and a lack of quantitative information about the initial species leaving the surface are still significant problems. The kinetics relating to most of the gas-phase reaction steps are becoming relatively well known because many involve small molecules, such as $\mathrm{OH}, \mathrm{CO}, \mathrm{NO}$, etc., which are common between various flames (mostly $\mathrm{C} / \mathrm{H} / \mathrm{O} / \mathrm{N}$ systems). However, some of the initial products leaving the surface can be relatively large molecules and can be relatively unique for a given compound (or family of compounds). The kinetics of the reaction steps involving these initial products is usually quite uncertain. Thus, the greatest uncertainties within the model are those that refer to the processes closest to the burning surface.

\section{MODELING OF PRE-MIXED COMPOUNDS}

\section{Monopropellant Models}

Combustion of several monopropellants including RDX [2, 3, 39, 40], HMX [41-43], GAP [44-45], BTTN [46], NG [32], AP [47, 48], and ADN [49] have been modeled by various researchers since about 1995, using detailed gas-phase chemical kinetics. These are listed in Table 1. They are divided and listed within their chemical families: nitramines, nitrate esters, and azides. AP and ADN are not categorized in a particular family because these compounds have diverse physical 
properties and undergo significantly different combustion chemistry. The compounds are generally made up of the elements $\mathrm{C}, \mathrm{H}, \mathrm{O}$, and $\mathrm{N}$, except for AP, which also includes $\mathrm{Cl}$, and $\mathrm{ADN}$, which does not include carbon. Those modeled include the oxidizer-rich AP and ADN, the relatively stoichiometric RDX, HMX, NG, and BTTN, and the fuel-rich binder, GAP. They have equilibrium flame temperatures ranging from $\approx 1400 \mathrm{~K}$ for AP to greater than $3000 \mathrm{~K}$ for HMX. Nitrate esters (double-base propellants) exhibit significant dark zones up to pressures as high as $30 \mathrm{~atm}[50,51]$. GAP is known to release significant energy in the condensed phase [52-54], while the nitramines RDX and HMX release most of their energy in the gas phase $[2,41]$. The latter contradicts the experimental data treatment by Zenin [4] who assumed that the major part of energy is released by burning nitramines in the condensed phase. This contradiction has not yet been resolved. It can thus be seen that the compounds that have been modeled, represent a significantly diverse set of ingredients with some rather unique combustion characteristics.

\section{Pseudo-Propellant Models}

Propellants are mixtures of two or more ingredients. To move from monopropellants to actual propellants, an intermediate condition has been considered. Mixtures of more than one ingredient have been considered as pseudo-propellants, if it can be assumed that the mixture is homogeneous. This assumption allows the use of monopropellant models based on premixed flames. Based on BDP-type calculations [55], the homogeneity assumption should be a reasonable approximation if the particulate phase of a propellant is of the order of ten microns or smaller.

The RDX-GAP system was selected for pseudopropellants because it is representative of advanced, non-AP propellants, and there were experimental data available [56-58]. As a result, both RDX-GAP [59, 60] and HMX-GAP [61] mixtures have been modeled. Subsequently RDX-GAP-BTTN [62] and AP-HTPB [63] were also modeled. In addition, the issue related to the existence of a dark-zone temperature plateau in a nitramine propellant flame has been addressed [54, 64]. Table 2 shows the pseudo-propellants that have been modeled. Pseudo-propellant models have typically been based on corresponding monopropellant models. In the models developed by Yang and colleagues [59, 61], the presence of particulates in the near-surface gas phase is included to provide a more complete description of the combustion-wave structure.

\section{MODEL INPUTS}

The model inputs include the following: the kinetic mechanisms for the condensed and gas phases, with their corresponding kinetic prefactors and activation energies; and the thermophysical and transport properties for the solid, condensed, and gas phases. Most model inputs are based on experimental data and theoretical values. In the few cases where specific values are not available, extrapolations of known data are necessary. Simulating the combustion of pseudo-propellants entails averaging some of the monopropellant properties.

\section{Condensed-Phase Properties}

The condensed-phase thickness typically ranges from $10 \mu \mathrm{m}$ to a few microns at rocket-motor operating pressures. Experimentally, characterizing the condensed phase is difficult, due to the phase heterogeneity, spatially small reaction zone, and steep temperature and concentration gradients [65]. Further complications, such as GAP forming a carbonaceous surface residue [54], can also occur in the condensed phase.

Decomposition experiments to analyze the condensed-phase processes have been conducted at different heating rates: low heating rate $\left(<10^{3} \mathrm{~K} / \mathrm{sec}\right)$, high heating rate (up to $10^{7} \mathrm{~K} / \mathrm{sec}$ ), and sometimes combustion conditions $\left(\approx 10^{7} \mathrm{~K} / \mathrm{sec}\right)$ [65]. Low heating rate studies typically provide the kinetic parameters for the global reactions, while high heating rate studies provide a more realistic set of species concentration data. Experiments are typically performed at subatmospheric pressures, since the flame is more spread out, and more accurate data can be obtained from available diagnostic techniques.

Condensed-Phase Kinetic Mechanism. Experimental data from the condensed phase include data of decomposition species concentrations at the surface and some corresponding kinetic parameters, typically only the activation energy, for the global reaction. Global kinetic mechanisms (distributed kinetics), based on these experimental data, have been developed and used in the models. The condensed-phase kinetic mechanisms typically include global decomposition steps, evaporation, and sometimes a few gas-phase reactions within the condensed-phase bubbles $[2,3]$.

Table 3 contains a general description of the kinetic mechanisms used in various models. It can be seen that the number of steps increases for pseudo-propellants due to the involvement of more than one ingredient. Based on the extent of understanding, the models describing some ingredients (such as RDX) have more detailed re- 
TABLE 1

Monopropellants Modeled with Detailed Kinetics

\begin{tabular}{|c|c|c|c|c|}
\hline Monopropellant & Chemical formula & Chemical family & Reference & Year \\
\hline \multirow{5}{*}{ RDX } & \multirow{5}{*}{$\mathrm{C}_{3} \mathrm{H}_{6} \mathrm{~N}_{6} \mathrm{O}_{6}$} & \multirow{5}{*}{ Nitramine } & Liau and Yang [3] & 1995 \\
\hline & & & Prasad and Beckstead [39] & 1997 \\
\hline & & & Davidson and Beckstead [2] & 1997 \\
\hline & & & Homan et al. [40] & 2000 \\
\hline & & & $\operatorname{Kim}[43]$ & 2000 \\
\hline \multirow{2}{*}{ HMX } & \multirow{2}{*}{$\mathrm{C}_{4} \mathrm{H}_{8} \mathrm{~N}_{8} \mathrm{O}_{8}$} & \multirow{2}{*}{ Nitramine } & Davidson and Beckstead [41] & 1996 \\
\hline & & & Prasad et al. [42] & 1998 \\
\hline \multirow{2}{*}{ GAP } & \multirow{2}{*}{$\left(\mathrm{C}_{3} \mathrm{H}_{5} \mathrm{~N}_{3} \mathrm{O}\right)_{n}$} & \multirow{2}{*}{ Azide } & Davidson and Beckstead [44] & 1996 \\
\hline & & & Puduppakkam and Beckstead [45] & 2005 \\
\hline NG & $\mathrm{C}_{3} \mathrm{H}_{5} \mathrm{~N}_{3} \mathrm{O}_{9}$ & Nitrate ester & Miller and Anderson [32] & 2000 \\
\hline BTTN & $\mathrm{C}_{4} \mathrm{H}_{7} \mathrm{~N}_{3} \mathrm{O}_{9}$ & Nitrate ester & Puduppakkam and Beckstead [46] & 2003 \\
\hline $\mathrm{AP}$ & $\mathrm{NH}_{4} \mathrm{ClO}_{4}$ & - & Jing et al. [48] & 1998 \\
\hline \multirow{2}{*}{$\mathrm{ADN}$} & \multirow{2}{*}{$\mathrm{NH}_{4} \mathrm{~N}\left(\mathrm{NO}_{2}\right)_{2}$} & \multirow{2}{*}{ - } & Liau et al. [49] & 1998 \\
\hline & & & Liau et al. [66] & 1999 \\
\hline
\end{tabular}

TABLE 2

Pseudo-Propellants Modeled with Detailed Kinetics

\begin{tabular}{l|l|l|l}
\hline Pseudo-Propellant & \multicolumn{1}{|c|}{ Reference } & Year & \multicolumn{1}{c}{ Composition range } \\
\hline AP/HTPB & Jeppson et al. [63] & 1998 & from 100\% AP to 77.5/22.5 AP/HTPB \\
\hline \multirow{2}{*}{ RDX/GAP } & Liau et al. [59] & 2000 & from 100\% RDX to 70/30 RDX-GAP \\
\cline { 2 - 4 } & Puduppakkam and Beckstead [60] & 2002 & from 100\% RDX to 70/30 RDX/GAP \\
\hline \multirow{2}{*}{ HMX/GAP } & Kim et al. [61] & 2002 & from 100\% HMX to 70/30 HMX/GAP \\
\hline RDX/GAP/BTTN & Puduppakkam and Beckstead [62] & 2003 & $70 / 9 / 21$ RDX/GAP/BTTN \\
\hline
\end{tabular}

action steps, while others (such as NG or BTTN) have fewer reactions, due to a lack of experimental data. In general, however, only a few, semi-global reaction steps represent the complex chemistry. Owing to the lack of experimental data, the ADN model did not include a condensed-phase mechanism at all [49].

Because of the lack of experimental data, the preexponential factors in the reaction-rate equations usually are the most uncertain and, as a result, are fitted to match the temperature and species concentrations at the surface. While this introduces some uncertainty, parametric studies are usually done in most modeling researches to evaluate the impact of parameter uncertainties on model results. Though the limitations in representing the condensed phase are serious, it needs to be appreciated that the extent of the condensedphase reactions are limited, and typically the majority of the heat release occurs in the gas phase. This tends to minimize the impact of the uncertainty due to the condensed-phase modeling.

A significant trend can be observed, based on the condensed-phase kinetic data reported in several experimental studies. Table 4 shows some of these similarities, based on a variety of references. For example, the experimentally determined condensed-phase activation energy is $\approx 50 \mathrm{kcal} / \mathrm{mole}$ for nitramines and $\approx 40 \mathrm{kcal} / \mathrm{mole}$ for nitrate esters and azides. Furthermore, the experimentally measured surface decomposition products are also very similar for members of the same family. For azides (e.g., GAP, BAMO, and AMMO), $\mathrm{N}_{2}$ was a dominant measured surface species (typically $\approx 40 \%$ ), along with smaller quantities of $\mathrm{CO}, \mathrm{CH}_{2} \mathrm{O}$, and $\mathrm{HCN}$ (e.g., see [53]). ADN and nitrate esters (BTTN, NG, PETN, NC, TMETN, TEGDN, NMMO, PGN, and PVN) have all been observed to yield large concentrations of the decomposition gases $\mathrm{NO}$ and $\mathrm{CO}$ at the surface [67-69]. 
TABLE 3

Kinetic Mechanisms Used in Combustion Models

(Number of Reactions and Species)

\begin{tabular}{|c|c|c|c|c|c|c|}
\hline \multirow{2}{*}{ Compound } & \multirow[b]{2}{*}{ Reference } & \multicolumn{3}{|c|}{ Condensed phase } & \multicolumn{2}{|c|}{ Gas phase } \\
\hline & & Decomposition & Evaporation & $\begin{array}{c}\text { Gaseous } \\
\text { reactions }\end{array}$ & Species & Reactions \\
\hline \multirow{3}{*}{ RDX } & Liau and Yang [3] & 2 & 1 & 1 & 45 & 232 \\
\hline & Prasad et al. [39] & 2 & at surface & 48 & 228 & \\
\hline & Davidson and Beckstead [2] & 2 & 1 & 1 & 45 & 232 \\
\hline \multirow{2}{*}{ HMX } & Prasad et al. [42] & 2 & at surface & 1 & 48 & 228 \\
\hline & Davidson and Beckstead [41] & 2 & 1 & 1 & 45 & 232 \\
\hline \multirow{2}{*}{ GAP } & Davidson and Beckstead [44] & 4 & - & - & 58 & 292 \\
\hline & Puduppakkam and Beckstead [45] & 2 & - & - & 74 & 460 \\
\hline $\mathrm{AP}$ & Jing et al. [48] & 4 & - & - & 33 & 79 \\
\hline BTTN & Puduppakkam [46] & 1 & 1 & - & 75 & 462 \\
\hline NG & Miller and Anderson [32] & 1 & - & - & 35 & 178 \\
\hline $\mathrm{ADN}$ & Liau et al. [49] & - & - & - & 33 & 180 \\
\hline $\mathrm{AP} / \mathrm{HTPB}$ & Jeppson et al. [63] & 9 & - & - & 44 & 157 \\
\hline \multirow{2}{*}{ RDX/GAP } & Liau et al. [59] & 4 & 1 & 5 & 71 & 520 \\
\hline & Puduppakkam and Beckstead [60] & 4 & 1 & 1 & 76 & 488 \\
\hline HMX/GAP & Kim et al. [61] & 4 & 1 & 5 & 74 & 532 \\
\hline RDX/GAP/BTTN & Puduppakkam and Beckstead [62] & 5 & 2 & 1 & 76 & 488 \\
\hline
\end{tabular}

This supports the logical observation that similar processes occur for members of the same chemical family. This is consistent with Zenin's observation of a "universal" law (i.e., a common activation energy) for nitrate ester compounds and with the Miller-Anderson approach to describe condensed-phase activity with an Arrhenius pyrolysis law.

These trends provide advantageous information for constructing a combustion mechanism. For instance, while modeling BTTN monopropellant combustion, there was a lack of experimental data for the activation energy [46]. However, extensive sets of data were available for other nitrate esters, including double-base propellants (NG-NC). Due to the similarities of the compounds, the NG-NC data were used in the BTTN condensed-phase model [46]. These trends also suggest that a model of a given ingredient can be extended to other ingredients of the same chemical family with relative ease. Several nitrate esters are of interest, including TMETN, TEGDN and PETN, and they could possibly be modeled with relative ease by extending the NG and BTTN models. Similarly, azides such as BAMO and AMMO could also be modeled by extending the GAP model.
Condensed-phase models for pseudo-propellants are based on the corresponding monopropellant models [59-63]. Reactions to account for the interaction between different ingredients in a pseudo-propellant have also been considered, where applicable [59, 61, 63].

Condensed-Phase Thermophysical and Transport Properties. The thermophysical properties of the liquid phase used are typically temperature-independent. Sometimes, the data have a large scatter, as in the case of GAP [45]. Parametric studies have been performed in such cases to assess the effect of variation in values of the properties. The value of specific heat affects the calculated condensed-phase heat release and temperature distribution significantly. The thermal conductivity affects the condensed-phase thickness but does not seem to affect other calculated characteristics significantly.

\section{Gas-Phase Properties}

Considering the wide range of ingredients available, it has been desirable to develop a common platform for modeling monopropellants and pseudo-propellants, to serve as a predictive tool. Analyzing the combustion of monopropellants and pseudo-propellants from an el- 
TABLE 4

\begin{tabular}{|c|c|c|c|c|c|}
\hline \multirow{2}{*}{$\begin{array}{l}\text { Chemical } \\
\text { family }\end{array}$} & \multirow{2}{*}{ Ingredients } & \multicolumn{2}{|c|}{ Activation energy } & \multirow{2}{*}{ Comments } & \multirow{2}{*}{$\begin{array}{l}\text { Kinetic } \\
\text { pathway }\end{array}$} \\
\hline & & $\mathrm{kcal} / \mathrm{mole}$ & References & & \\
\hline Nitramines & RDX, HMX & $\begin{array}{c}\approx 50 \\
\text { (lots of } \\
\text { scatter) }\end{array}$ & $\begin{array}{l}\text { From summaries } \\
\text { of Refs. [70], [72] }\end{array}$ & - & $\begin{array}{l}\text { Parallel reactions; } \\
\text { one forming } \mathrm{CH}_{2} \mathrm{O} \\
\text { and the other } \mathrm{HCN}^{2}\end{array}$ \\
\hline \multirow{4}{*}{ Nitrate esters } & NG & $\begin{array}{c}34.4 \pm 1.5,35.1 \\
36,40-45,46.9\end{array}$ & $\begin{array}{l}\text { From summaries } \\
\text { of Refs. [71], [72] }\end{array}$ & \multirow{4}{*}{$\begin{array}{c}\text { Several } \\
\text { nitrate esters } \\
\text { have a similar } \\
\text { activation energy of } \\
\approx 40 \mathrm{kcal} / \mathrm{mole}\end{array}$} & \multirow{4}{*}{$\begin{array}{l}\text { Initial bond breaking } \\
\text { is the breaking of the } \\
\mathrm{O}-\mathrm{NO}_{2} \text { bond }[71-74]\end{array}$} \\
\hline & $\mathrm{NC}$ & $\begin{array}{l}30.7,41.2 \\
43,47\end{array}$ & $\begin{array}{l}\text { From summaries } \\
\text { of Ref. }[71]\end{array}$ & & \\
\hline & $\mathrm{NG}+\mathrm{NC}$ & $35.6,41,45.3$ & $\begin{array}{l}\text { From summaries } \\
\text { of Refs. [71], [72] }\end{array}$ & & \\
\hline & $\begin{array}{c}\mathrm{CH}_{3} \mathrm{O}-\mathrm{NO}_{2} \\
\mathrm{C}_{2} \mathrm{H}_{5} \mathrm{O}-\mathrm{NO}_{2} \\
\end{array}$ & $\begin{array}{c}39.5 \\
38\end{array}$ & $\begin{array}{l}\text { From summaries } \\
\text { of Ref. [71] }\end{array}$ & & \\
\hline \multirow{3}{*}{ Azides } & GAP & $\begin{array}{c}32.4,37,39.3 \\
39.4 \pm 1.1,41.5 \\
41.6,42.2,43 \\
43.2 \pm 2.8,43.5\end{array}$ & {$[52,53,75-81]$} & \multirow{3}{*}{$\begin{array}{l}\text { Several azides } \\
\text { have a similar } \\
\text { activation energy of } \\
\approx 40 \mathrm{kcal} / \mathrm{mole}\end{array}$} & \multirow{3}{*}{$\begin{array}{c}\text { Initial bond breaking is } \\
\text { the azide bond }\left(-\mathrm{N}_{3}\right) \\
\text { breaking to release } \mathrm{N}_{2} \\
{[52,53,82-84]}\end{array}$} \\
\hline & BAMO & $\begin{array}{c}36,40.8 \pm 1.9 \\
42.7\end{array}$ & {$[75,77,85]$} & & \\
\hline & AMMO & $40.9 \pm 0.8$ & {$[77]$} & & \\
\hline
\end{tabular}

ementary level aids in predicting the burning characteristics and can be achieved by using detailed chemical kinetic mechanisms in the gas phase.

Gas-Phase Kinetic Mechanism. The gas phase is relatively well understood. Several detailed kinetic mechanisms for gaseous products of solid propellants have been developed independently over the years. These include the Yetter mechanism developed for RDX combustion (45 species/232 reaction steps) [38], the Gas Research Institute (GRI) mechanism developed for natural gas combustion (53/325) [86], the Miller-Anderson mechanism developed for NG combustion (35/178) [32], the Korobeinichev-Ermolin mechanism developed for AP combustion (33/79) [87] and AP/CTPB combustion (35/58) [88], and the Lin mechanism developed for ADN combustion (33/180) [49]. These mechanisms have been developed based on both experimental data and theoretical predictions.

The Yetter mechanism for an RDX flame was published in 1995 after a significant program comparing available kinetic parameters to various known reaction steps and simple flames. Subsequently it has been used by Prasad et al. [39], Liau and Yang [3], and Davidson and Beckstead [2] as the basis for modeling RDX combustion. HMX was subsequently modeled with a few modifications to the Yetter mechanism [41, 42].
NG combustion was modeled using the Miller-Anderson mechanism, which was developed to simulate the dark zone and ignition delay characteristics of gun propellants [32]. AP combustion was modeled by Jing et al. [48] using a modified Ermolin mechanism [87].

An effort has been made to integrate various mechanisms to form a single mechanism to describe the combustion of several monopropellants and pseudopropellants. The similarities between the mechanisms for various compounds make this approach attractive. Most propellants are made up of the elements $\mathrm{C}, \mathrm{H}$, $\mathrm{O}$, and $\mathrm{N}$. While the initial species in the condensed phase are markedly different for different ingredients, they eventually decompose to similar gas-phase species. For instance, $\mathrm{CO}, \mathrm{CH}_{2} \mathrm{O}, \mathrm{HCN}, \mathrm{NH}_{3}, \mathrm{H}_{2} \mathrm{O}$, and $\mathrm{N}_{2}$ have been reported, in varying concentrations, in the flame of nitramine RDX, azide GAP, and nitrate ester NG. Consequently, it appears that gas-phase mechanisms developed for a particular ingredient can be used for other ingredients, provided the initial decomposition schemes can be determined. This has especially been the case for pseudo-propellants. AP-HTPB combustion was modeled [63], for instance, using reactions from the $\mathrm{AP}-$ CTPB [88] and AP [87] mechanisms, and the mechanism of GRI [86]. The extra reactions from the mechanism of GRI and the AP mechanism were reported to 
result in a flame temperature that agreed much better with the equilibrium value [63] than those reported in [88]. RDX/GAP has been modeled [59] using a combination of the RDX mechanism [38] and the mechanism of GRI [86]. GAP [45], BTTN [46], RDX/GAP [60] and RDX/GAP/BTTN [62] pseudo-propellants have been modeled by Puduppakkam et al. using essentially a single, combined gas-phase mechanism, which was made up of reactions from the RDX [38], AP [87], and NG [32] mechanisms, and the mechanism of GRI [86] with some additional reactions from Park and Lin [89]. Many of the reactions are common between various mechanisms described above, and redundant reaction steps were eliminated.

Some of the kinetic parameters are somewhat uncertain or have been optimized for the combustion of a particular compound. For instance, some of the preexponential factors in the mechanism of GRI have been optimized for natural gas combustion. When using these reactions for modeling the combustion of other compounds, there is a potential that they may not represent the chemistry well. Some reactions need further review [62] but, as a whole, the integrated mechanisms seem to provide consistent results. This indicates that it may be possible to assemble a single comprehensive mechanism that can eventually be applied to model several more compounds. That would imply that the only different information needed to model different ingredients would potentially be about the condensed-phase processes.

Gas-Phase Thermophysical and Transport Properties. Most of the thermophysical and transport properties for the gas-phase species under consideration are reasonably well documented in the literature. Since the gas-phase species are common to other reaction systems, such as methane, many of those data have been used for solid propellant combustion product gases. The properties are often available in a temperaturedependent format.

\section{MODEL RESULTS AND DISCUSSION}

\section{Monopropellants}

The calculated combustion characteristics from most models include the pressure and temperature sensitivities of the burning rate, species and temperature profiles, and surface and flame temperatures. The burning rate is the calculated characteristic of most interest. Results from these models are typically consistent with the experimental burning rate data. Figure 1 shows the calculated burning rates $r$ for several monopropellants. The corresponding data points have not been

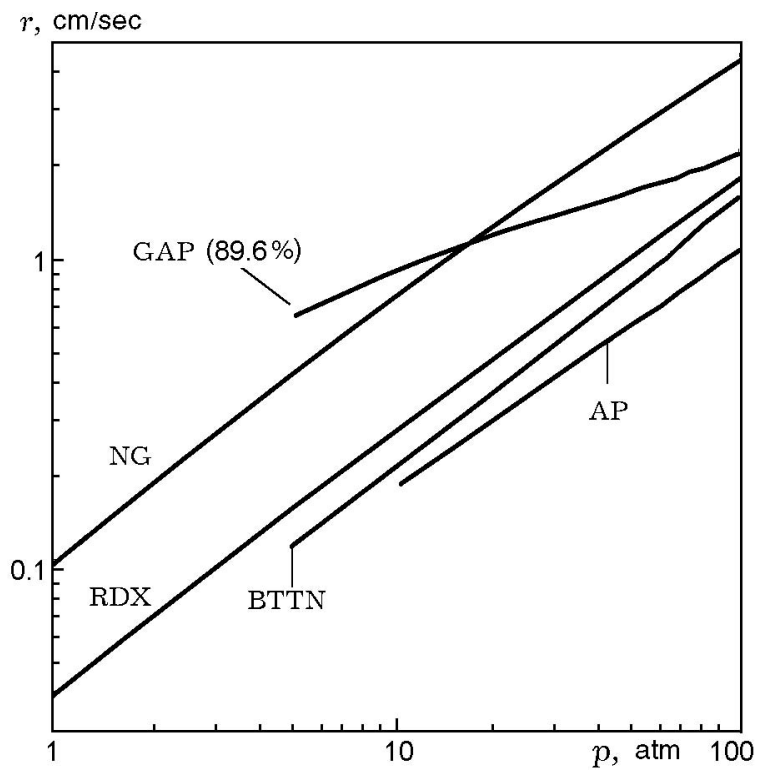

Fig. 1. Calculated burning rates for NG [32], AP [48], RDX [2], GAP [45], and BTTN [46], based on detailed mechanisms.

included, as they would obscure the graph. A detailed comparison can be observed in each of the references from the original papers. Various model calculations agree with the experimental data well, but to varying degrees. The calculated burning rate of BTTN matched $67 \%$ of the experimental data within $\pm 10 \%$ and all of the data within $\pm 15 \%$. For AP, $60 \%$ of the data were within $\pm 5 \%$ and $83 \%$ were within $\pm 7 \%$. For RDX, $60 \%$ of the data were within $\pm 10 \%$ and $85 \%$ within $\pm 15 \%$. For GAP, $80 \%$ of the data were within $\pm 10 \%$. For NG, $82 \%$ of the data were within $\pm 15 \%$ in the range of pressures 1 to 100 atm.

The burning rates of monopropellants shown in Fig. 1 vary by almost an order of magnitude. One of the interesting features is the lack of direct correspondence between the flame temperature and the burning rate for these monopropellants. GAP has one of the highest burning rates in Fig. 1, although it has one of the lowest flame temperatures $(\approx 1400 \mathrm{~K})$. The high burning rate of GAP is apparently due to a large condensed-phase heat release. The flame temperatures of RDX, BTTN, and NG are similar $(\approx 3000 \mathrm{~K})$, yet their burning rates vary considerably.

The pressure exponents of the calculated burning rates shown in Fig. 1 vary over a wide range, $0.4-0.85$, for different ingredients. These values typically agree well with experimental data, i.e., within $\pm 5 \%$. The calculated condensed-phase heat release is not significantly affected by pressure, apparently, due to the global nature of the condensed-phase kinetics. The gas-phase reaction rates, however, are dependent on pressure. With 


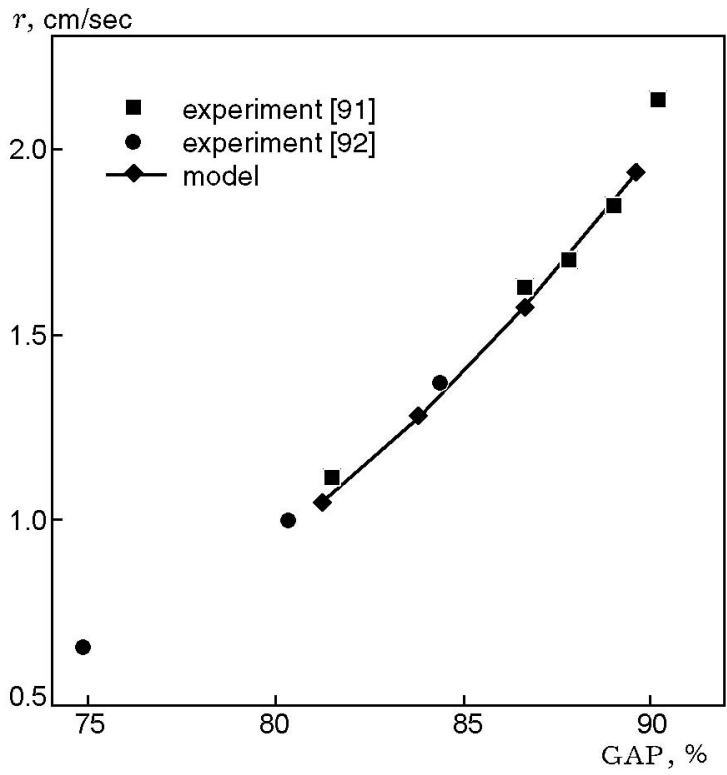

Fig. 2. Burning rate of GAP-curative mixture versus the GAP percentage.

increasing pressure, the flame moves closer to the surface, thus, increasing the heat feedback to the surface. Hence, the pressure exponent is a measure of the model accuracy, in terms of the calculated gas-phase heat feedback and its impact on the burning rate.

The burning rate for GAP has been observed to be strongly dependent on the amount of curative with the GAP polymer [54, 90, 91]. Kubota et al. [92] reported a correlation between the $-\mathrm{N}_{3}$ bond energy contained within a unit mass of GAP and the burning rate. The burning rate increases significantly with increasing GAP content, essentially doubling as the percentage of GAP varies from $\approx 81 \%$ to $90 \%$.

The calculated burning rate at 70 atm is shown in Fig. 2 as a function of the azide content of four different formulations with the GAP content varying from 81 to $89 \%$. The agreement between model calculations and experimental data in Fig. 2 is excellent. The large effect of the azide content points to the significant impact of the condensed-phase energy release. The burning rate of GAP is high since the energy is released close to the surface, even though it is a relatively low overall amount of energy.

An advantage of detailed models is that, in addition to calculating the burning rate and its pressure exponent, the models make it possible to calculate the temperature sensitivity, the temperature and species profiles, and the surface and flame temperatures. Experimental data for temperature and species profiles are not often available, but if available, they provide a more comprehensive validation of the models and a

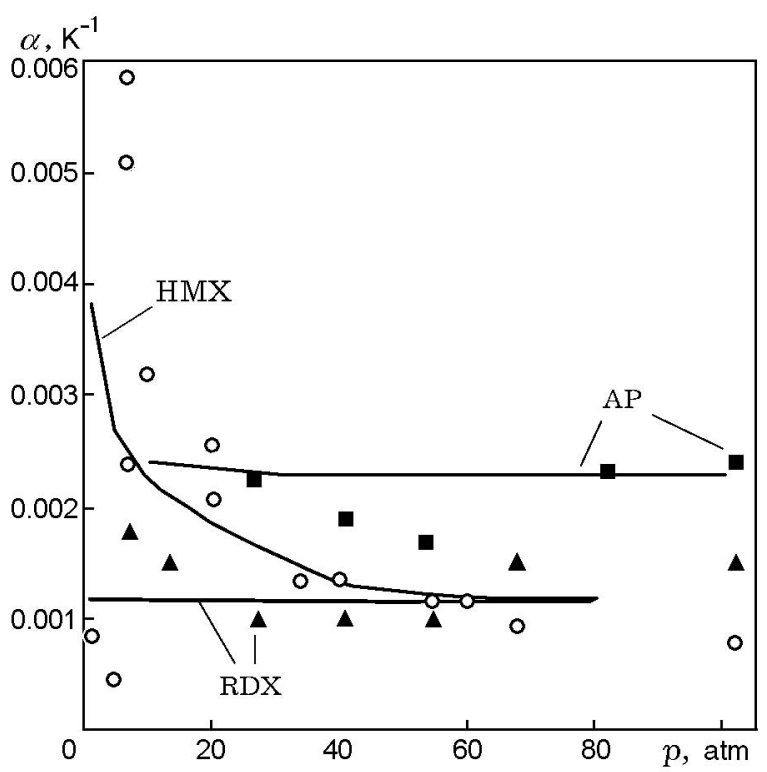

Fig. 3. Calculated temperature sensitivities for RDX [2], HMX [36, 37], and AP [48] (curves) compared with experimental data [93] (points).

more comprehensive view of the combustion process.

The temperature sensitivity is affected significantly by the condensed-phase heat release, (i.e., a larger energy release close to the surface results in a higher dependence of the burning rate on the initial temperature). For instance, GAP, which has a high condensedphase heat release, also has a high temperature sensitivity. Also, parametric studies from some models indicate that the physical properties of the condensed phase can affect the temperature sensitivity significantly $[45,46]$. The temperature sensitivity of the burning rate $(\alpha)$ for the range of compounds modeled varies from $\approx 0.001 \mathrm{~K}^{-1}$ for nitramines (RDX and HMX) and $\approx 0.004 \mathrm{~K}^{-1}$ for nitrate esters $(\mathrm{BTTN})$ to $\approx 0.01 \mathrm{~K}^{-1}$ for azides (GAP). Some of the calculated values are plotted in Fig. 3.

The temperature sensitivity is probably the hardest characteristic to match with experimental data, partly due to the uncertainties in condensed-phase parameters, and partly because the temperature sensitivity is a derivative quantity. In general, the calculated temperature sensitivity agrees reasonably well with experimental data qualitatively and decreases with increasing pressure. However, there have been instances when the calculated values are not consistent with experimental data. For example, RDX and HMX both have very low values of temperature sensitivity $\left(\approx 0.001 \mathrm{~K}^{-1}\right)$ at pressures above $\approx 50 \mathrm{~atm}$; at pressures approaching one atmosphere, however, RDX has a value of slightly less than $0.002 \mathrm{~K}^{-1}$ and HMX has a value of $\approx 0.005 \mathrm{~K}^{-1}$ 
[93]. Most models [41-43] have not been able to reproduce this behavior. However, a recent modeling approach that includes the effects of surface tension of the bubbles in the liquid layer [36, 37] has been successful in calculating the observed difference in the temperature sensitivity of RDX and HMX at low pressures, as is shown in Fig. 3.

Table 5 lists the concentrations of species entering the gas phase, as used in different monopropellant models, including a nitramine (RDX), a nitrate ester (NG), an azide (GAP), AP, and ADN. The concentrations are primarily based on experimental data. Table 5 shows an interesting trend: Monopropellants with considerably different structures and compositions decompose to form similar gaseous species at the surface, although with considerably different compositions. The largest concentrations are marked in bold. The information in Table 5 provides some valuable insights into the combustion mechanisms. For instance, one of the most dominant factors affecting the burning rate is the gasphase heat feedback. The near-surface gas-phase reactions, which depend on the species concentrations and their reactivity, influence the gas-phase heat feedback considerably and are, thus, of particular significance for the burning rate calculations. AP, for instance, has a large concentration of reactive species close to the surface, enabling a high heat feedback, even though the flame temperature is low $(\approx 1400 \mathrm{~K})$.

The species concentrations at the surface are also instructive in identifying processes occurring farther from the surface. For instance, NG and ADN have large concentrations of $\mathrm{NO}_{2}$ and/or $\mathrm{N}_{2} \mathrm{O}$ at the surface. These species usually react to form NO, large concentrations of which at $\approx 1500 \mathrm{~K}$ are known to cause a dark zone. Indeed, NG has a large dark zone, even at high pressures, and $\mathrm{ADN}$ has two dark zones. On the other hand, $\mathrm{RDX}$ does not have a large concentration of $\mathrm{NO}_{2}$ or $\mathrm{N}_{2} \mathrm{O}$ at the surface, and even though its elemental composition $\left(\mathrm{C}_{3} \mathrm{H}_{6} \mathrm{~N}_{6} \mathrm{O}_{6}\right)$ is similar to $\mathrm{NG}\left(\mathrm{C}_{3} \mathrm{H}_{5} \mathrm{~N}_{3} \mathrm{O}_{9}\right)$ and BTTN $\left(\mathrm{C}_{4} \mathrm{H}_{7} \mathrm{~N}_{3} \mathrm{O}_{9}\right)$, it does not exhibit a dark zone under self-deflagration conditions.

The species profiles have been compared with experimental data where available. For RDX, the modeling results match experimental data well $[2,3]$. For BTTN, general trends are available from experimental data, and the calculated concentrations appear consistent with the experimental observations. Figure 4 compares the calculated species profiles of ADN of Liau et al. [49] with the experimental data of Korobeinichev et al. [94], and the calculated values can be seen to be in good agreement with the experimental data.

Figure 5 shows some of the calculated temperature profiles at $5 \mathrm{~atm}$ of the monopropellants RDX,

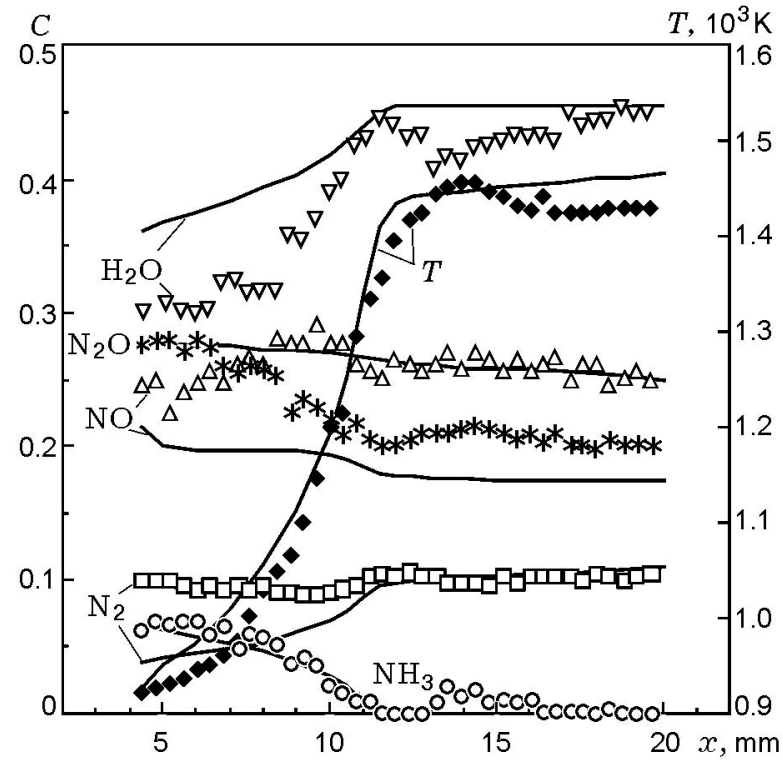

Fig. 4. Calculated profiles of temperature and species concentrations of ADN gas flame at 6 atm: the curves and points refer to the calculation [49] and experiment [94]; $x$ is the distance from the surface.

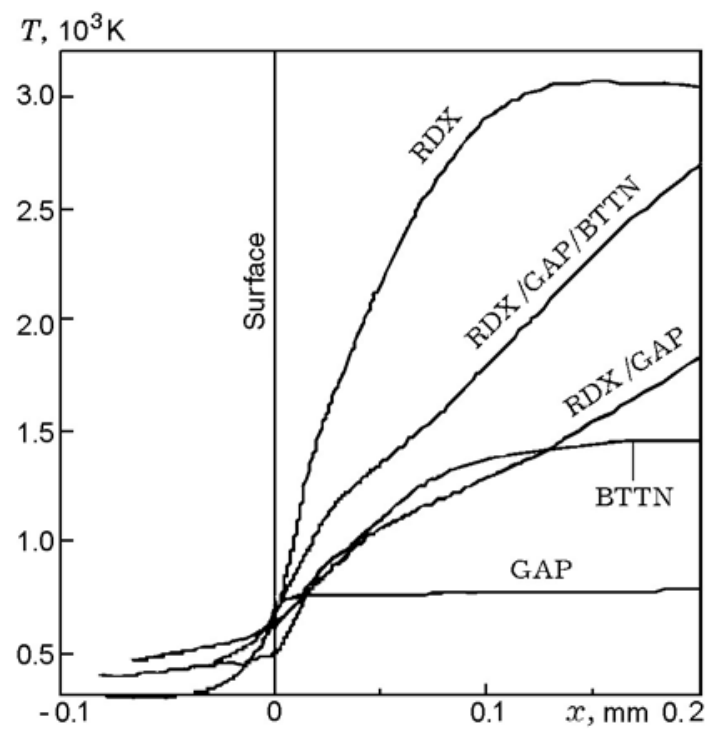

Fig. 5. Calculated temperature profiles for monopropellants and pseudo-propellants at 5 atm.

GAP, and BTTN, and pseudo-propellants made from them. The large gas-phase heat feedback of RDX is illustrated by the large temperature gradient near the surface. GAP has a very low calculated flame temperature, consistent with experimental data, due to its fuelrich character. BTTN has a dark zone at a temperature of $\approx 1500 \mathrm{~K}$ due to the slow chemistry of NO. The darkzone length is based on the plateau in the calculated 
TABLE 5

Species Mole Fraction Values at the Surface Used in the Models ( $p=5 \mathrm{~atm})$

\begin{tabular}{|c|c|c|c|c|c|c|c|c|c|c|c|c|}
\hline \multirow{2}{*}{ Monopropellant } & \multicolumn{6}{|c|}{ Nitrogen-containing species } & \multicolumn{2}{|c|}{$\begin{array}{l}\text { Carbon } \\
\text { species }\end{array}$} & \multicolumn{4}{|c|}{ Other species } \\
\hline & $\mathrm{N}_{2}$ & $\mathrm{NO}$ & $\mathrm{HCN}$ & $\mathrm{NH}_{3}$ & $\mathrm{NO}_{2}$ & $\mathrm{~N}_{2} \mathrm{O}$ & $\mathrm{CO}$ & $\mathrm{CH}_{2} \mathrm{O}$ & $\mathrm{O}_{2}$ & $\mathrm{H}_{2} \mathrm{O}$ & $\mathrm{HClO}_{4}$ & Other \\
\hline $\operatorname{RDX}[2]$ & - & 0.08 & 0.17 & - & 0.08 & 0.08 & - & 0.08 & - & 0.08 & - & $0.4 \operatorname{RDX}$ (gas) \\
\hline AP [48] & - & - & - & 0.26 & - & 0.05 & - & - & 0.12 & 0.17 & 0.21 & $0.09 \mathrm{HCl}$ \\
\hline \multirow[b]{2}{*}{ GAP $(89.6 \%)[45]$} & \multirow[b]{2}{*}{0.18} & \multirow[b]{2}{*}{-} & \multirow[b]{2}{*}{0.15} & \multirow[b]{2}{*}{0.03} & \multirow[b]{2}{*}{ - } & \multirow[b]{2}{*}{-} & \multirow[b]{2}{*}{0.11} & \multirow[b]{2}{*}{0.03} & \multirow[b]{2}{*}{ - } & \multirow[b]{2}{*}{0.06} & \multirow[b]{2}{*}{-} & $0.18 \mathrm{C}$ (solid) \\
\hline & & & & & & & & & & & & $\begin{array}{c}0.1 \mathrm{CH}_{4} \\
0.08 \mathrm{H}_{2}\end{array}$ \\
\hline $\mathrm{ADN}[94]$ & 0.1 & 0.23 & - & 0.07 & - & 0.28 & - & - & - & 0.3 & - & $0.2 \mathrm{HNO}_{3}$ \\
\hline NG-Hatch [32] & - & - & - & - & 0.5 & - & - & 0.33 & - & - & - & $0.17 \mathrm{HCO}$ \\
\hline NG-Levy [32] & - & - & - & - & 0.33 & - & 0.17 & 0.33 & - & - & - & $0.17 \mathrm{HONO}$ \\
\hline NG-MSM4 [32] & - & - & - & - & - & - & 0.17 & - & - & - & - & $\begin{array}{c}\mathbf{0 . 5} \mathrm{HONO} \\
0.33 \mathrm{HCO}\end{array}$ \\
\hline
\end{tabular}

temperature profiles, and eventually ends at $x=7.1 \mathrm{~cm}$ from the surface for this case $(p=5 \mathrm{~atm})$, after which the temperature rises to the thermodynamically equilibrium value of $3050 \mathrm{~K}$. The calculated dark-zone length $(L)$ and temperature appear consistent with experimental data [95]. Profiles such as in Figs. 4 and 5, along with species profiles, contribute to better understanding of the combustion process.

The calculated dark-zone lengths of BTTN as a function of pressure are shown in Figure 6, and they compare well with the available experimental data on BTTN [95]. Dark zones have also been observed for other nitrate esters and double-base propellants $[71,51$, 96]. The dark-zone length data in Fig. 6 of Kubota [51] for a double-base propellant are of the same order of magnitude as the experimental data and calculated values for BTTN, indicating the similarities in the combustion processes. The slope of the calculated dark zones is 1.73 , while the values reported for double-base propellants include 1.8 [51] and 2.2 [96].

Dark zones are caused by a combined effect of the residence time of the reactive species in the reaction zone due to fluid transport and the kinetics of the chemical reactions. Nitrate esters such as NG and BTTN exhibit large dark zones, and the models have captured that effect $[32,46]$. Figure 7 a shows the calculated temperature profiles at several pressures for BTTN, and a dark zone can be seen even at relatively high pressures. The length of the dark zone, which decreases significantly with increasing pressure, is consistent with experimental data.

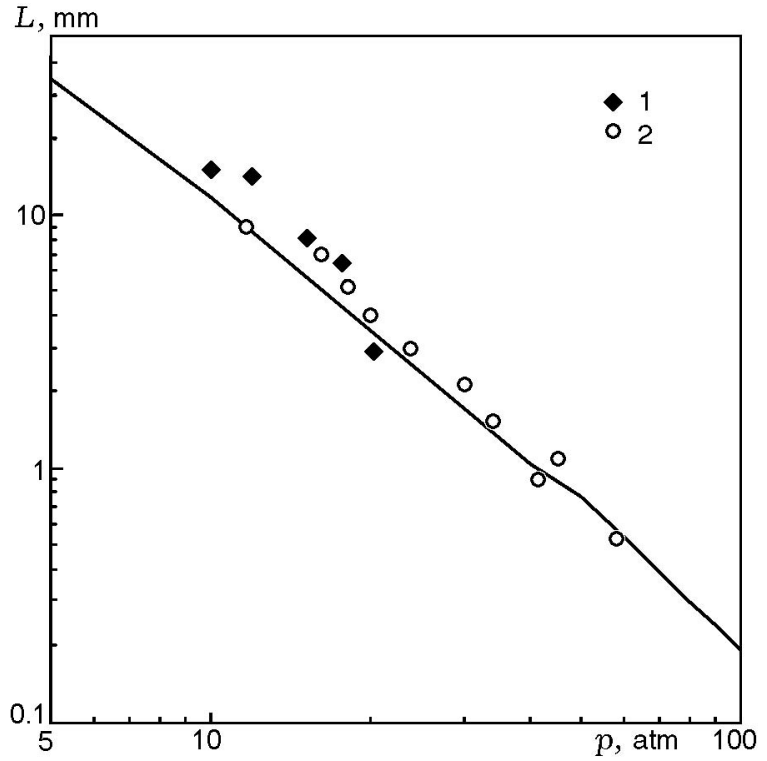

Fig. 6. Dark-zone length versus pressure: the curve refers to the calculation for BTTN, and the points refer to the experimental data for BTTN (points 1 [95]) and double-base propellants (points 2 [51]).

RDX exhibits an interesting characteristic. During laser-assisted combustion at near-atmospheric pressures, RDX exhibits a dark zone, while there is no dark zone under self-deflagration conditions. The models have been able to predict this characteristic, as is shown in Fig. 7b. The calculated dark-zone length and temperature are consistent with experimental data $[2,3]$. The 

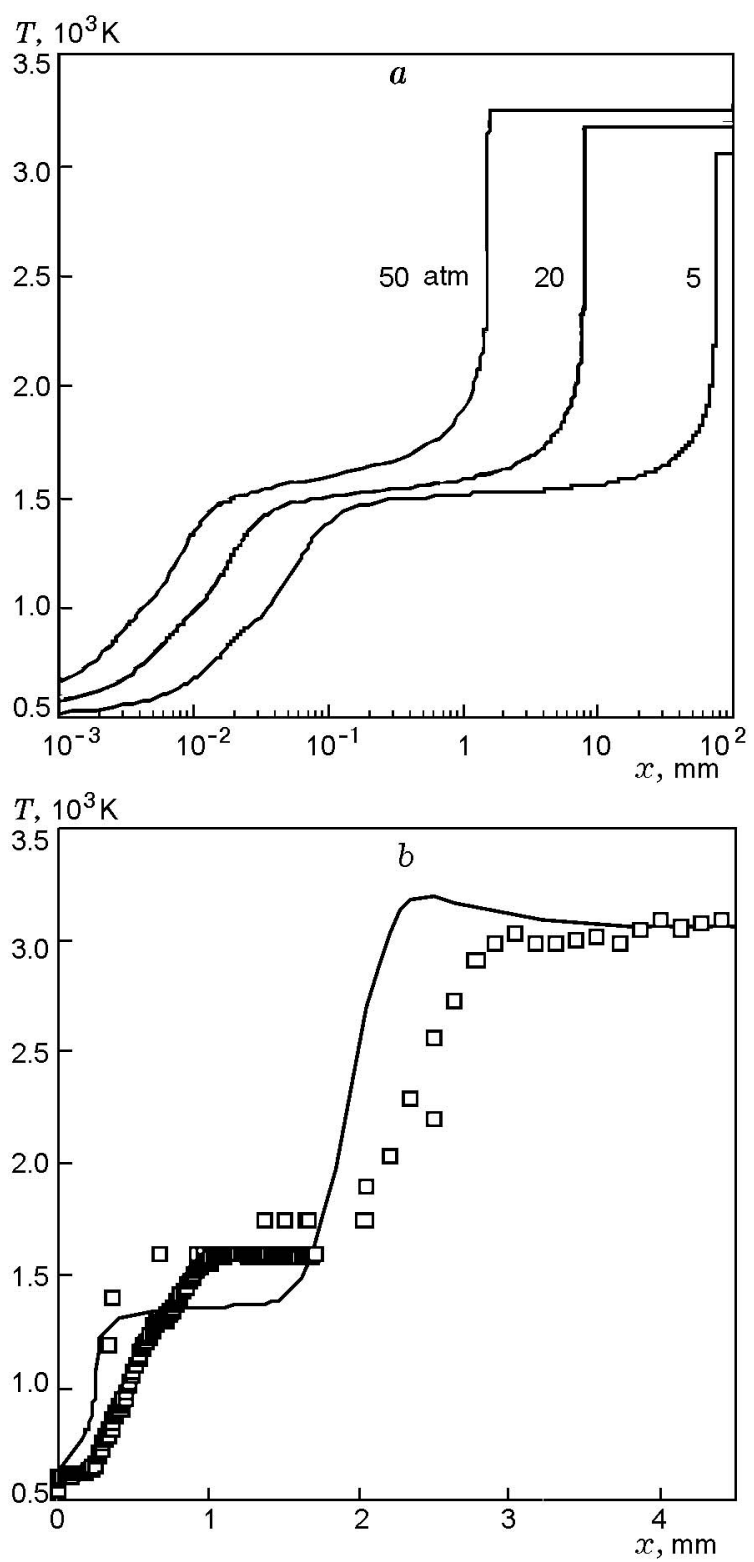

Fig. 7. Temperature profiles: (a) calculated profiles for BTTN [46]; (b) calculated and experimental profiles for RDX at $1 \mathrm{~atm}$ under laser-assisted combustion [2].

model predicts a dark zone due to the increased burning rate caused by the added laser heat flux. Indeed, the calculated dark-zone length increases with increasing laser flux [30].

The surface temperature signifies the start of the gas-phase process, and thus matching the calculated value with experimental data provides another test of the model accuracy. The adiabatic flame temperature, while based on the equilibrium assumption, depends on the kinetic mechanism, since the kinetic mechanism has to predict the correct final species concentrations. Thus, matching the adiabatic flame temperature with equilibrium results is somewhat of a test of the gas-phase kinetic mechanism. In general, the model calculations match the equilibrium well. One of the exceptions to this, however, is GAP. The experimental GAP flame temperatures are $\approx 1100 \mathrm{~K}$, while the thermodynamically equilibrium values are $\approx 1400 \mathrm{~K}$ at nominal pressures. This discrepancy is apparently due to the fuelrich character of GAP, which results in the formation of a non-equilibrium, carbonaceous residue [45]. The presence of this residue indicates that the combustion process is not completed.

\section{Pseudo-Propellants}

Pseudo-propellants burn quite differently compared to monopropellants, and the characteristics are not always intuitively obvious. One of the main reasons for that is the different chemistry, which affects the spatial distribution of energy release, and thus the burning rate characteristics. The composition of the pseudo-propellant affects the concentration of species exiting the condensed phase, thus altering the nearsurface gas-phase reactions and the ensuing gas-phase heat feedback. The propellant composition also affects the heat release in the condensed phase. These factors affect the burning rate characteristics. Modeling with detailed kinetics should, thus, help resolve most of these complexities. Comparing the calculated combustion characteristics of pseudo-propellants with experimental data also forms one of the tests of the approach and the kinetic mechanisms used.

Pseudo-propellants with several ingredients and varying compositions have been modeled. RDX/GAP pseudo-propellants (90/10, 80/20, and $70 / 30$ RDX/GAP) have been modeled by Liau et al. [59] and Puduppakkam and Beckstead [60]. Figure 8 shows the calculated burning rates of the two models as functions of the composition, in comparison with experimental data [56]. Figure 8 shows an interesting trend, with both monopropellant RDX and GAP having much higher burning rates than the mixture. While the calculated values from Liau et al. [59] and Puduppakkam and Beckstead [60] differ, probably due to different gas-phase kinetic mechanisms and condensed-phase treatment, they both show a consistent trend of decreasing burning rate with increasing GAP content (0-30\%). The decrease in the calculated burning rate with increasing GAP content is attributed to a decrease in the gas-phase heat feedback, which is due to an increase in concentration of inerts such as 


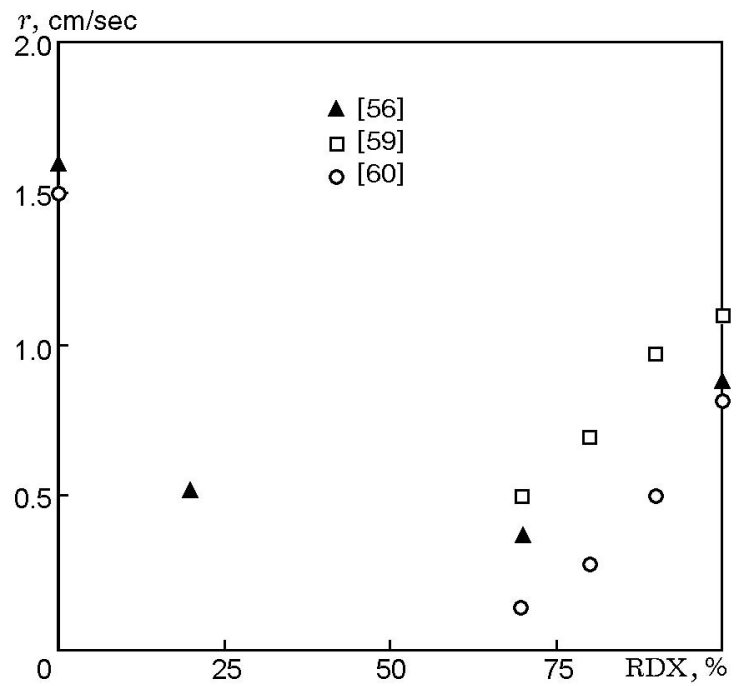

Fig. 8. RDX/GAP pseudo-propellant burning rate versus composition (at $p=34 \mathrm{~atm}$ ). Comparison of experimental data [56] and results calculated by models [59] and [60].

$\mathrm{N}_{2}$ from GAP decomposition [59,60]. The condensedphase heat release increases with the GAP content but is apparently insufficient to compensate for the decrease in the gas-phase heat feedback. It may be noted that the gas-phase mechanism used was not specifically developed for RDX/GAP, but it still gives the right trends. Also, the 80/20 RDX/GAP pseudo-propellant exhibits a dark zone at $p=1$ atm during laser-assisted combustion, and the model calculations are consistent with experimental data [60].

AP/HTPB has also been modeled as a pseudopropellant [63], but it shows exactly the opposite trend of RDX/GAP. The model [63] was developed assuming a premixed mixture of AP and HTPB, simulating a homogeneous binder. The kinetic mechanism was based on a similar AP/CTPB mechanism [88], the AP monopropellant mechanism [87], and some reaction steps from the mechanism of GRI [86]. The model calculations were compared to experimental data for two mixtures of AP and HTPB. The size of AP particles in experiments was small enough $(12 \mu \mathrm{m})$ for the mixture to be homogeneous. As a monopropellant, AP has a moderate burning rate [93], but when combined with HTPB, which cannot self-sustain combustion as a monopropellant, the mixture has a much higher burning rate due to more stoichiometric conditions and a higher flame temperature [97]. The calculated behavior of the burning rate versus the AP/HTPB ratio [63] matches the experimental data of [97], as is shown in Fig. 9. The model [63] predicted a higher burning rate due to enhanced

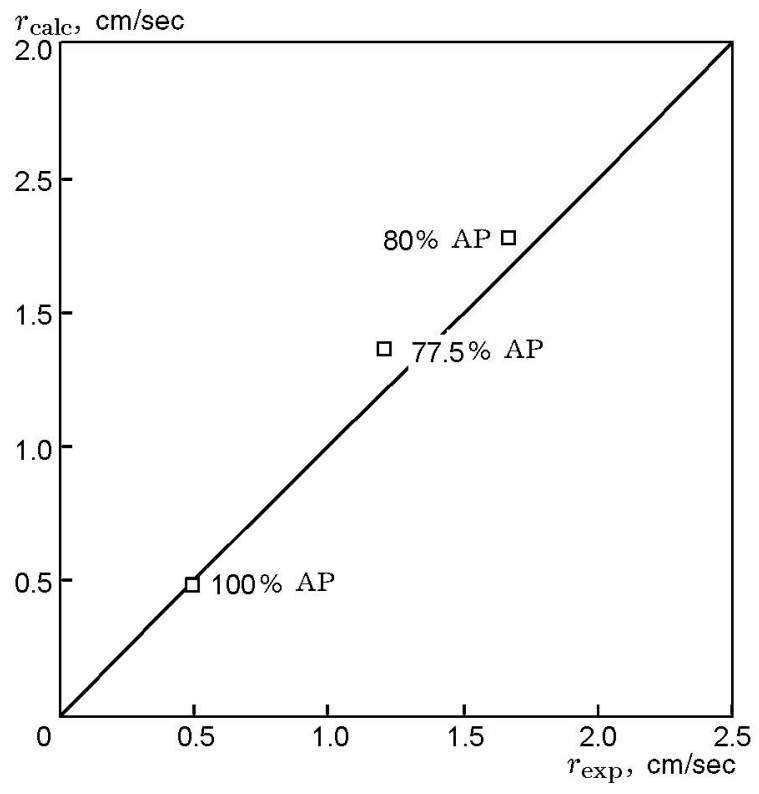

Fig. 9. Comparison of the experimental [93, 97] and calculated $[48,63]$ burning rates of $\mathrm{AP} / \mathrm{HTPB}$ compositions with mass ratios of components $100 / 0$, $77.5 / 22.5$, and $80 / 20$ at $p=34$ atm.

heat feedback from the gas phase.

Another pseudo-propellant formulation was made up of $70 \%$ RDX, 9\% GAP, and $21 \%$ BTTN [95]. The RDX was a bimodal mix of $17 \mu \mathrm{m}(70 \%)$ and $1.7 \mu \mathrm{m}$ (30\%). The small particles were used to simulate a homogeneous mixture. BTTN was added to the formulation, because a pure RDX/GAP mixture produced a solid carbonaceous material, prohibiting the possibility of making laser diagnostic measurements. Parr and Hanson-Parr reported detailed flame structure measurements for that formulation [98]. A detailed mechanism was developed for the RDX/GAP/BTTN pseudopropellant as discussed earlier. The final mechanism used consisted of 76 species and 488 reaction steps [62]. None of the kinetic parameters was varied within the mechanism in going from the monopropellant calculations to the pseudo-propellant calculation.

It is worth mentioning that the calculations were performed without advance knowledge of the experimental burning rate data. Thus, the simulations represent a blind prediction of the burning rate. The calculated rates are compared to the experimental data of [62] in Fig. 10, which also includes the calculated monopropellant burning rates of the individual components. The calculated results for the pseudo-propellant were within $4 \%$ of the experimental data, except at 1 atm. The burning rate of the pseudo-propellant is smaller than that of all constituting ingredients, 


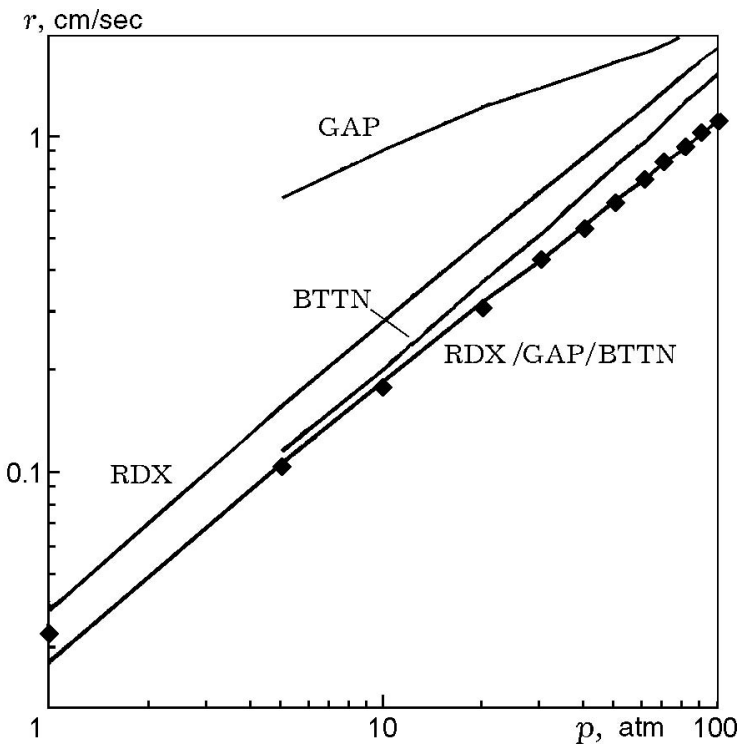

Fig. 10. Burning rate of the RDX/GAP/BTTN pseudo-propellant and constituting ingredients: the points refer to the experimental data of [95] for the RDX/GAP/BTTN pseudo-propellant; the curves refer to the calculations of [62]; the burning rate of the pseudo-propellant was calculated without advance knowledge of experimental data.

and the model has been able to capture that effect. The constituting ingredients have widely varying flame structures, pressure exponents $(\approx 0.4-0.85)$, and temperature sensitivities $\left(\approx 0.001-0.01 \mathrm{~K}^{-1}\right)$. The model, nonetheless, predicted consistent values of both the pressure exponent (0.8) and the temperature sensitivity (0.0012-0.0014 $\left.\mathrm{K}^{-1}\right)$ for the mixture, compared with the experimental data of [95].

The results for both mono- and pseudo-propellants are very encouraging. The kinetic mechanisms seem to be consistent, suggesting that a mechanism could possibly be developed containing reactions that could represent several different compounds and the corresponding propellant mixtures. This could be a significant step towards further a priori predictions. While the quantitative results are not always accurately calculated, modeling results typically provide the right trends, which help understand the combustion process better.

\section{CONCLUSIONS}

Tremendous progress has been achieved in the last ten years with respect to modeling the combustion of solid propellant ingredients. The gas-phase kinetic mechanisms seem to represent the chemistry of several monopropellants and pseudo-propellants consistently well, although some reactions may need further review. In spite of the constraints, the current state of modeling appears very promising. The combustion of several monopropellants and pseudo-propellant compositions has been analyzed from an elementary level, and these models have helped understand the overall combustion process better. The major constraint on solid propellant combustion modeling currently is the insufficient understanding of the chemical reaction pathways and reaction rates in the condensed phase.

It appears that, by assembling a large database of monopropellant models, a comprehensive mechanism could be developed, capable of simulating pseudopropellants of varying compositions and ingredients. Most of the pseudo-propellant models discussed in this paper have been based on the corresponding monopropellant models. As has been discussed, several monopropellants have already been modeled, and it should be possible to extend that capability to ingredients of the same chemical families with relative ease.

The current state of modeling, thus, appears to be headed toward a priori predictions. While this outlook is very positive, describing the condensed-phase chemistry is a significant constraint. Various simplifications seem to result in the capability to calculate correct trends but not precise quantitative results. One of the other main constraints is the assumption of the one-dimensional combustion wave structure, which neglects the effects of the particle size and flame expansion. Modeling is, thus, not yet a predictive tool, but at the current stage it can be used as a useful guide. It seems that in the near future these combustion models could help in the formulation of advanced propellants.

\section{REFERENCES}

1. M. W. Beckstead, J. E. Davidson, and Q. Jing, "A comparison of solid monopropellant combustion and modeling," AIAA Paper No. 97-0586 (1997).

2. J. E. Davidson and M. W. Beckstead, "Improvements to steady-state combustion modeling of cyclotrimethylenetrinitramine," J. Propul. Power, 13, No. 3, 375-383 (1997).

3. Y. C. Liau and V. Yang, "Analysis of RDX Monopropellant combustion with two-phase subsurface reactions," J. Propul. Power, 11, No. 4, 729-739 (1995)

4. A. Zenin, "HMX and RDX: Combustion mechanism and influence on modern double-base propellant combustion," ibid., pp. 752-758.

5. N. E. Ermolin and V. E. Zarko, "Investigation of the properties of a kinetic mechanism describing the chemical structure of RDX flames. I. Role of individual reactions and species," Combust., Expl., Shock Waves, 37, No. 2, 123-147 (2001). 
6. M. W. Beckstead, R. L. Derr, and C. F. Price, "A model of composite solid-propellant combustion based on multiple flames," AIAA J., 8, No. 12, 2200-2207 (1970).

7. M. S. Miller, "In search of an idealized model of homogeneous solid propellant combustion," Combust. Flame, 46, 51-73 (1982).

8. L. K. Gusachenko, V. E. Zarko, V. Ya. Zyryanov, and V. P. Bobryshev, Modeling the Combustion Processes in Solid Propellants [in Russian], Nauka, Novosibirsk (1985); see also L. K. Gusachenko and V. E. Zarko, "Analysis of contemporary models of steady state combustion of composite solid fuels," Combust., Expl., Shock Waves, 22, No. 6, 643-653 (1986).

9. M. W. Beckstead and K. P. McCarty, "Calculated combustion characteristics of nitramine monopropellants," in: Proc. 13th JANNAF Combustion Meeting, Vol. I (1976), pp. 57-68.

10. G. M. Knott, M. Q. Brewster, and T. L. Jackson, "Simplified modeling of composite propellant combustion with finite Peclet number," in: 35th JANNAF Combustion Subcommittee Meeting, CPIA Pub. No. 680, Vol. I (1998), pp. 655-669.

11. J. Buckmaster, T. L. Jackson, and J. Yao, "An elementary discussion of propellant flame geometry," Combust. Flame, 117, 541-552 (1999).

12. S. Kochevets, J. Buckmaster, and T. L. Jackson, "Random propellant packs and the flames they support," in: 36th AIAA/ASME/SAE/ASEE Joint Propulsion Conf. and Exhibit (Huntsville July 16-19, 2000), AIAA Paper No. 2000-3461 (2000);

13. A. Hegab et al., "The burning of periodic sandwich propellants," ibid., AIAA Paper No. 2000-3459 (2000).

14. T. L. Jackson et al., "The burning of $3 \mathrm{D}$ random-pack heterogeneous propellants," in: 37 th AIAA/ASME/SAE/ASEE Joint Propulsion Conf. and Exhibit (Salt Lake City, UT, July 8-11, 2001), AIAA Paper No. 2001-3952 (2001).

15. G. M. Knott, T. L. Jackson, and J. Buckmaster, "Random packing of heterogeneous propellants," AIAA J., 39, No. 4, 678-686 (2001).

16. X. Wang, T. L. Jackson, and L. Massa, "Numerical simulation of heterogeneous propellant combustion by a level set method," J. Combust. Theory Model., 8, 227254 (2004).

17. M. D. Smooke, R. A. Yetter, T. P. Parr, and D. M. Hanson-Parr, "Modeling two-dimensional ammonium perchlorate diffusion flames," in: 36th JANNAF Combustion Meeting, CPIA Publ. No. 691, Vol. I (1999), pp. 359-368.

18. W. Cai and V. A. Yang, "Model of AP/HTPB composite propellant combustion," in: 38th Aerospace Sciences Meeting and Exhibit (Reno, Jan. 10-13, 2000), AIAA Paper No. 2000-0311 (2000).
19. S. A. Felt and M. W. Beckstead, "A Model of the AP/HTPB diffusion flame," in: 39th JANNAF Combustion Meeting (2003).

20. L. Massa, T. L. Jackson, and M. Short, "Numerical solution of three-dimensional heterogeneous solid propellants," J. Combust. Theory Model., 7, 579-602 (2003).

21. J. J. Cor and M. R. Branch, "Structure and chemical kinetics of flames supported by solid propellant combustion," J. Propul. Power, 11, No. 4, 704-716 (1995).

22. J. A. Miller and C. T. Bowman, "Mechanism and modeling of nitrogen chemistry in combustion," Progr. Energ. Combust. Sci., 15, No. 4, 287-338 (1987).

23. R. J. Kee, F. M. Rupley, and J. A. Miller, "CHEMKIN II: A Fortran chemical kinetics package for the analysis of gas-phase chemical kinetics," Sandia National Laboratories, Report No. SAND89-8009 (1989).

24. R. J. Kee, J. F. Grcar, M. D. Smooke, and J. A. Miller, "A fortran program for modeling steady, laminar, onedimensional, premixed flames," Sandia National Laboratories, Report No. SAND85-8240 (1989).

25. W. W. Erikson and M. W. Beckstead, "Modeling unsteady monopropellant combustion with full chemical kinetics," AIAA Paper No. 98-0804 (1998).

26. W. W. Erikson and M. W. Beckstead, "Modeling pressure and heat flux responses of nitramine monopropellants with detailed chemistry," AIAA Paper No. 99-2498 (1999).

27. V. Yang and Y. C. Liau, "A time-accurate analysis of RDX monopropellant combustion with detailed chemistry," in: 32nd JANNAF Combustion Meeting, CPIA Publ. No. 631, Vol. I (1995), pp. 57-68.

28. Y. C. Liau, E. S. Kim, and V. Yang, "A comprehensive analysis of laser-induced ignition of RDX monopropellant," Combust. Flame, 13, 1680-1698 (2001).

29. Y. C. Liau and J. L. Lyman, "Modeling laser-induced ignition of nitramine propellants with condensed and gasphase absorption," Combust Sci. Technol, 174, No. 3, 141-171 (2002).

30. K. V. Meredith and M. W. Beckstead, "Laser-induced ignition modeling of HMX," in: 39th JANNAF Combustion Meeting (2003).

31. K. V. Meredith and M. W. Beckstead, "Fast-cookoff modeling of HMX," ibid.

32. M. S. Miller and W. R. Anderson, "Energetic-material combustion modeling with elementary gas-phase reactions: a practical approach," in: V. Yang, T. B. Brill, and Wu-Zhen Ren (eds.), Progress in Astronautics and Aeronautics, Vol. 185: SolidPropellant Chemistry, Combustion, and Motor Interior Ballistics, Ch. 2.12, AIAA (2000), pp. 504-531.

33. N. E. Ermolin, O. P. Korobeinichev, A. G. Tereshchenko, and V. M. Fomin, "Kinetic calculations and mechanism definition for reactions in an ammonium perchlorate flame," Combust., Expl., Shock Waves, 18, No. 2, 180-188 (1982). 
34. N. E. Ermolin, O. P. Korobeinichev, L. V. Kuibida, and V. M. Fomin, "Study of the kinetics and mechanism of chemical reactions in hexogen flames," Combust., Expl., Shock Waves, 22, No. 5, 544-552 (1986).

35. A. A. Zenin, "Universal dependence for heat liberation in the k-phase and gas macrokinetics in ballistic powder combustion," Combust., Expl., Shock Waves, 19, No. 4, 444-446 (1983).

36. E. B. Washburn, M. W. Beckstead, and M. L. Gross, "Condensed phase model for HMX decomposition," in: 38th JANNAF Combustion Meeting, CPIA Publ. No. 712, Vol. I (2002), pp. 33-42.

37. E. B. Washburn and M. W. Beckstead, "Multi-phase effects in the combustion of HMX and RDX," in: 39th JANNAF Combustion Meeting (2003).

38. R. A. Yetter, F. L. Dryer, M. T. Allen, and J. L. Gatto, "Development of gas-phase reaction mechanism for nitramine combustion," J. Propul. Power, 11, No. 4, 683-697 (1995).

39. K. Prasad, R. A. Yetter, and M. D. Smooke, "An eigenvalue method for computing the burning rates of RDX propellants," Combust. Sci. Technol., 124, 35-82 (1997).

40. B. E. Homan, M. S. Miller, and J. A. Vanderhoff, "Absorption diagnostics and modeling investigations of RDX flame structure," Combust. Flame, 120, 301-317 (2000).

41. J. E. Davidson and M. W. Beckstead, "A three-phase model of HMX combustion," in: 26th Symp. (Int.) on Combustion, The Combustion Inst. (1996), pp. 19891996.

42. K. Prasad, R. A. Yetter, and M. D. Smooke, "An eigenvalue method for computing the burning rates of HMX propellants," Combust. Flame, 115, 406-416 (1998).

43. E. S. Kim, "Modeling and simulation of laser-induced ignition of RDX monopropellant and steady-state combustion of HMX/GAP pseudo propellant," Ph. D. Thesis, The Pennsylvania State University (2000).

44. J. E. Davidson and M. W. Beckstead, "A mechanism and model for GAP combustion," in: 33rd JANNAF Combustion Meeting, CPIA Publ. No. 653, Vol. II (1996), pp. 91-100.

45. K. V. Puduppakkam and M. W. Beckstead, "Combustion modeling of glycidyl azide polymer with detailed kinetics," Combust. Sci. Technol., 177, No. 9, 1661-1697 (2005).

46. K. V. Puduppakkam, "Modeling the steady-state combustion of solid propellant ingredients with detailed kinetics," Ph. D. Dissertation, Brigham Young University (2003).

47. N. E. Ermolin, "Kinetic parameters of overall gas-phase reactions for propellants based on ammonium perchlorate and polybutadiene binder," Combust., Expl., Shock Waves, 29, No. 4, 508-515 (1993).
48. Q. Jing, M. W. Beckstead, and M. B. Jeppson, "Influence of AP solid phase decomposition on temperature profile and sensitivity," AIAA Paper No. 98-0448 (1998).

49. Y. C. Liau, V. Yang, M. C. Lin, and J. Park, "Analysis of ammonium dinitramide (ADN) combustion with detailed chemistry," in: 35th JANNAF Combustion Subcommittee Meeting (1998).

50. C. A. Heller and A. S. Gordon, "Structure of the gas phase combustion region of a solid double base propellant," J. Phys. Chem., 59, 773-777 (1955).

51. N. Kubota, "Determination of plateau burning effect of catalyzed double-base propellant," in: 17th Int. Symp. on Combustion (1979), pp. 1435-1441.

52. N. Kubota and T. Sonobe, "Combustion mechanism of azide polymer," Propellants, Explos. Pyrotech., 13, 172177 (1988).

53. J. F. Trubert, J. Duterque, and G. Lengellé, "Study of the condensed phase degradation and combustion of glycidyl azide polymer," in: Energetic Materials, Proc. 30th Int. Annu. Conf. of ICT, Karlsruhe, Germany (1999).

54. A. A. Zenin and S. V. Finjakov, "Physics of GAP combustion," in: 38th Aerospace Sciences Meeting and Exhibit, AIAA Paper No. 2000-1032 (2000).

55. M. W. Beckstead, "Combustion mechanisms of composite solid propellants," in: 19th JANNAF Combustion Meeting, CPIA Publ. No. 366, Vol. II (1982), pp. 93100.

56. J. E. Flanagan, D. O. Woolery, R. L. Kistner, and M. W. Beckstead, "Combustion characteristics of GAP/RDX gumstocks," in: 24th JANNAF Combustion Meeting, CPIA Publ. No. 476, Vol. III (1987), pp. 29-38.

57. N. Kubota and T. Sonobe, "Burning rate catalysis of azide/nitramine propellants," in: Proc. 23rd Int. Symp. on Combustion, The Combustion Inst. (1990), pp. 13311337.

58. C. J. Tang, Y. J. Lee, and T. A. Litzinger, "The chemical and thermal processes of GAP/nitramine pseudopropellants under $\mathrm{CO}_{2}$ laser heating," in: 34th JANNAF Combustion Meeting, CPIA Publ. No. 662, Vol. II (1997), pp. 491-504.

59. Y. C. Liau, V. Yang, and S. T. Thynell, "Modeling of RDX/GAP propellant combustion with detailed chemical kinetics," in: V. Yang, T. B. Brill, and WuZhen Ren (eds.), Progress in Astronautics and Aeronautics, Vol. 185: Solid Propellant Chemistry, Combustion, and Motor Interior Ballistics, Ch. 2.11, AIAA Inc., Reston (2000), pp. 477-500.

60. K. V. Puduppakkam and M. W. Beckstead, "RDX/GAP pseudo-propellant combustion modeling," in: 38th JANNAF Combustion Meeting, CPIA Publ. No. 712, Vol. I (2002) pp. 143-156.

61. E. S. Kim, V. Yang, and Y. C. Liau, "Modeling of HMX/GAP pseudo-propellant combustion," Combust. Flame, 131, 227-245 (2002). 
62. K. V. Puduppakkam and M. W. Beckstead, "Combustion modeling of RDX/GAP/BTTN pseudopropellant," in: 39th JANNAF Combustion Meeting (2003).

63. M. B. Jeppson, M. W. Beckstead, and Q. Jing, "A kinetic model for the premixed combustion of a fine AP/HTPB composite propellant," in: AIAA 36th Aerospace Sciences Meeting and Exhibit, AIAA Paper No. 98-0447 (1998);

64. Y. C. Liau and V. Yang, "On the existence of dark-zone temperature plateau in RDX monopropellant flame," AIAA Paper No. 97-0589 (1997).

65. T. B. Brill, M. W. Beckstead, J. E. Flanagan, et al., "Chemical speciation and dynamics in the surface combustion zone of energetic materials," J. Propul. Power, 18, No. 4, 824-834 (2002).

66. Y. C. Liau, V. Yang, M. C. Lin, and J. Park, "An improved model of ammonium dinitramide (ADN) combustion with detailed chemistry," in: 36th JANNAF Combustion Meeting (1999).

67. B. D. Roos and T. B. Brill, "Thermal decomposition of energetic materials 82 . Correlations of gaseous products with the composition of aliphatic nitrate esters," Combust. Flame, 128, 181-190 (2002).

68. R. I. Hiyoshi and T. B. Brill, "Thermal decomposition of energetic materials 83. Comparison of the pyrolysis of energetic materials in air versus argon," Propellants, Expl., Pyrotech., 27, 23-30 (2002).

69. J. K. Chen and T. B. Brill, "Thermal decomposition of energetic materials 50. Kinetics and mechanism of nitrate ester polymers at high heating rates by SMATCH/FTIR spectroscopy," Combust. Flame, 85, 479-488 (1991).

70. T. L. Boggs, "The thermal behavior of RDX and HMX," in: K. K. Kuo and M. Summerfield (eds.), Progress in Astronautics and Aeronautics, Vol. 90: Fundamentals of Solid Propellant Combustion, Amer. Inst. of Aeronaut. and Astronaut., New York (1984), pp. 121-175.

71. G. Lengellé, A. Bizot, J. Duterque, and J. F. Trubert, "Steady-state burning of homogeneous propellants," ibid., Ch. 7, pp. 361-398.

72. R. A. Fifer, "Chemistry of nitrate ester and nitramine propellants," ibid., Ch. 4, pp. 177-219.

73. B. L. Crawford, C. Huggett, and J. J. McBrady, "The mechanism of the burning of double-base propellants," J. Phys. Colloid Chem., 54, No. 6, 854-862 (1950).

74. R. E. Wilfong, S. S. Penner, and F. Daniels, "An hypothesis for propellant burning," ibid., pp. 863-871.

75. M. Farber, S. P. Harris, and R. D. Srivastave, "Mass spectrometric kinetic studies on several azido polymers," Combust. Flame, 55, 203-211 (1984).

76. B. B. Goshgarian, "The mechanism of nitramine and advanced propellant ingredient initial thermochemical decomposition," AFRPL-TR-82-040, Edwards Air Force Base, Edwards (1982).
77. J. K. Chen and T. B. Brill, "Thermal decomposition of energetic materials 54. Kinetics and near-surface products of azide polymers AMMO, BAMO and GAP in simulated combustion," Combust. Flame, 87, 157-168 (1991).

78. S. Dhar and H. Singh, "Burn rate and catalysis behavior of GAP based CMDB propellants," in: 31st AIAA/ASME/SAE/ASEE Joint Propulsion Conf. and Exhibit (San Diego, July 10-12, 1995), AIAA Paper No. 95-2586 (1995).

79. G. Lengellé, B. Fourest, J. C. Godon, and C. Guin, "Condensed phase behavior and ablation rate of fuels for hybrid propulsion," AIAA Paper No. 93-2413 (1993).

80. O. P. Korobeinichev, L. V. Kuibida, A. G. Shmakov, and A. A. Paletsky, "GAP decomposition and combustion chemistry studied by molecular beam massspectrometry," in: 37th AIAA Aerospace Sciences Meeting and Exhibit, AIAA Paper No. 99-0596 (1999).

81. Y. Oyumi, "Thermal decomposition of azide polymers," Propellants, Explos., Pyrotech., 17, 226-231 (1992).

82. H. Arisawa and T. B. Brill, "Thermal decomposition of energetic materials 71. Structure-decomposition and kinetic relationships in flash of glycidyl azide polymer (GAP)," Combust. Flame, 112, 533-544 (1998).

83. Y. Haas, Y. B. Eliahu, and S. Welner, "Infrared laserinduced decomposition of GAP," Combust. Flame, 96, 212-220 (1994).

84. C.-J. Tang, Y. Lee, and T. A. Litzinger, "Simultaneous temperature and species measurements of the glycidyl azide polymer (GAP) propellant during laser-induced decomposition," Combust. Flame, 117, 244-256 (1999).

85. E. Kimura and Y. Oyumi, "Effects of copolymerization ratio of BAMO/NMMO and catalyst on sensitivity and burning rate of HMX propellant," Propellants, Explos., Pyrotech., 20, 215-221 (1995).

86. M. Frenklach, T. Bowman, G. Smith, and B. Gardiner, "GRI-MECH 3.0," Downloaded from http://www.me.berkeley.edu/gri_mech/.

87. N. E. Ermolin, "Model for chemical reaction kinetics in perchloric acid-ammonia flames," Combust., Expl., Shock Waves, 31, No. 5, 555-565 (1995).

88. N. E. Ermolin, O. P. Korobeinichev, V. M. Fomin, and A. A. Chernov, "Study of flame structure for mixed solid fuels based on ammonium perchlorate and polybutadiene rubber," Combust., Expl., Shock Waves, 28, No. 4, 372-377 (1992).

89. J. Park and M. C. Lin, "A mass spectrometric study of the $\mathrm{NH}_{2}+\mathrm{NO}_{2}$ reaction," J. Phys. Chem. A, 101, No. 14, 343-347 (1997).

90. M. B. Frankel, L. R. Grant, and J. E. Flanagan, "Historical development of glycidyl azide polymer," J. Propul. Power, 8, 560-563 (1992).

91. J. Flanagan, D. Woolery, and R. Kistner, "Fundamental studies of azide decomposition and combustion," AFRPL-TR-86-094 (1986). 
92. N. Kubota, T. Sonobe, A. Yamamoto, and H. Shimizu, "Burning rate characteristics of GAP propellants," J. Propul. Power, 6, 686-689 (1990).

93. A. I. Atwood, T. L. Boggs, P. O. Curran, et al., "Burning rate of solid propellant ingredients. P. 1: Pressure and initial temperature effects," J. Propul. Power, 15, No. 6, 740-747 (1999).

94. O. P. Korobeinichev, L. V. Kuibida, A. A. Paletsky, and A. G. Shmakov, "Molecular-beam mass spectrometry to ammonium dinitramide combustion chemistry studies," J. Propul. Power, 14, No. 6, 991-1000 (1998).

95. T. Parr and D. Hanson-Parr, "RDX/GAP/BTTN propellant flame studies," Combust. Flame, 127, 1895-1905 (2001).
96. C. A. Heller and A. S. Gordon, "Structure of the gas phase combustion region of a solid double base propellant," J. Phys. Chem., 59, 773-777 (1955).

97. R. L. Foster and R. R. Miller, "The burn rate temperature sensitivity of aluminized and non-aluminized HTPB propellants," in: JANNAF Propulsion Meeting (Monterey, March 11-13, 1980), CPIA Publ. No. 315, Vol. IV (1981), pp. 667-693.

98. T. Parr and D. Hanson-Parr, "BTTN flame structure," in: 38th JANNAF Combustion Subcommittee Meeting, CPIA Publ. No. 712, Vol. I (2002), pp. 43-49. 